\title{
Preclinical Assessment of Infant Formula
}

\author{
Bo Lönnerdal \\ Department of Nutrition, University of California, Davis, Calif., USA
}

\section{Key Words}

Safety $\cdot$ Infant formula $\cdot$ Novel ingredients $\cdot$ Toxicity

\begin{abstract}
Infant formulas are the sole or predominant source of nutrition for many infants and are fed during a sensitive period of development and may therefore have short- and long-term consequences for infant health. Preclinical safety assessment therefore needs to include both short-term and longterm studies in animals. It is recommended that procedures are instituted by which experts may serve as independent scientists for companies developing novel products, without having their integrity compromised, and later serve the legislative institutions. A two-level assessment approach to determine the potential toxicity of a novel ingredient, its metabolites, and their effects in the matrix on developing organ systems has been suggested by IOM. This appears reasonable, as novel ingredients can be of different levels of concern. The use of modern methods in genomics and proteomics should be considered in these evaluation processes as well as novel methods to evaluate outcomes, including metabolomics and molecular techniques to assess the microbiome.

\section{Introduction}

Infancy is a very vulnerable period with many organs being immature and undergoing rapid development. It is therefore reasonable that concerns for safety of products used for infants should be scrutinized closer than foods for adults who are less sensitive and have developed homeostatic mechanisms to cope with nutrient inadequacies and excesses [1]. Similarly, any toxicity may be exacerbated in infants who have less developed protective mechanisms.

In this article, the emphasis will be put on the addition of novel ingredients to infant formula or infant foods. This does not intend to mean that other aspects, such as formula/food composition, quality control (content of both nutrients and potential toxicants), processing, packaging, and bacteriological/viral contamination, are unimportant, but there are regulations for minima and maxima of nutrients in infant formulas [2,3], changing processing parameters, packaging material, and ingredient sources $[4,5]$, which are widely accepted and not controversial. Addition of novel ingredients, however, is a more recent area of concern and under intense discussion. It is essential that the evaluation of such ingredients, which usually are accompanied by health claims, will fol-

\section{KARGER \\ Fax +4161306 1234 \\ E-Mail karger@karger.ch}

www.karger.com
(C) 2012 S. Karger AG, Basel

0250-6807/12/0603-0196\$38.00/0

Accessible online at:

www.karger.com/anm
Dr. Bo Lönnerdal

Department of Nutrition

University of California

Davis, CA 95616 (USA)

Tel. +1 530752 8347, E-Mail bllonnerdal@ucdavis.edu 
low a rigorous scientific approach and not be affected by alarmists $[6,7]$. The Institute of Medicine (IOM) of the Food and Nutrition Board therefore assembled a Consensus Report in 2004, reviewing aspects needing consideration and giving some suggestions [8]. However, many recommendations were vague and few of them seem to have been implemented. Further, the number of potential novel ingredients that are possible and potentially beneficial to add has rapidly increased in recent years.

It should be considered that infant formulas are the sole or predominant source of nutrition for many infants and that they are fed during a sensitive period of development and may therefore have short- and long-term consequences for infant health. Preclinical safety assessment therefore needs to include both short-term and long-term studies in animals.

\section{Establishment of Expert Panels}

For the present GRAS (Generally Regarded As Safe) process, qualified experts are required to evaluate the safety of the ingredient under review. There are, however, no specifications for the composition of the expert panel. It is considered important that the panel consists of unbiased experts with high scientific integrity. The IOM recommends that the panel should contain a pediatrician [8]. This is reasonable, but this pediatrician should have expertise in infant feeding. It would also be desirable that experts with knowledge in nutrition and food technology would be part of the panel. Early input into the preclinical and clinical assessment of novel infant formulas will be essential, as any regulatory process is likely to consist of an evaluation of what tests will be needed for each individual component. It would therefore be beneficial if the expert panel is established at an early stage of the process of adding a novel component to infant formula, so that appropriate safety tests are included upfront. Procedures should be instituted by which experts may serve as independent scientists for companies developing novel products, without having their integrity compromised, and later serve the legislative institutions, possibly by the companies communicating their selection of experts with these institutions at an early stage. The pool of acknowledged scientists within each area of expertise is fairly limited, and this would increase consistency in the evaluation process. It would also avoid the possibility that the manufacturer's experts recommend a certain set of safety assessments and the legislative agency then demands another set of assessments, unnecessarily prolonging the process.

Preclinical Assessment of Infant Formula

\section{Animal Models}

Any preclinical assessment of infant formula safety will need to include animal models. As a routine, PER (Protein Efficiency Ratio) tests in rats are usually conducted, but these are unlikely to show any adverse effects unless the protein source is grossly inadequate or has been damaged by processing. Rodent models (rats, mice) are often used for toxicity tests, largely for ease of use, but it should be recognized that differences in metabolism and development limit their value. They do, however, have value in the process of evaluating both safety and bioactivity of novel compounds, but the tissue(s) or organ systems assessed have to be chosen carefully and depend on the compound being evaluated as well as the potential biological activity exerted. The piglet model is increasingly used [911] and has many advantages with regard to similarities in gastrointestinal physiology, organs, and biochemistry. A slight disadvantage is that infant formula cannot be used as such; differences in nutrient requirements makes it necessary to modify concentrations of several nutrients, e.g., protein, calcium, and phosphorus, which means that a product different from that fed to human infants is evaluated. Assessment of learning (cognitive development) is also limited in piglets. The non-human primate (rhesus, baboon) is most likely the best possible animal model that can be used and it has been used in many studies on formula modifications [12-15]. Infant formula can be fed as such from birth to 5 months of age as the nutrient requirements of infant monkeys are very similar to those of human infants. Their physiology and biochemistry are very similar, and sophisticated tests for evaluating behavior, development, and learning are available. There are, however, few places where this can be done, it is an expensive model to use, and for ethical reasons, the number of animals available for dissection is limited.

\section{Preclinical Assessments Range from Cellular-Molecular through Whole-Animal Studies}

The IOM Committee recommended the use of a twolevel assessment approach to determine the potential toxicity of the ingredient, its metabolites, and their effects in the matrix on developing organ systems [8]. This appears reasonable, as the novel ingredients can be of different levels of concern. The Committee did not, however, connect the assessment level to the level of concern for the added ingredient; presumably, this would be done on a case-by-case evaluation. It is obvious that a component,

Ann Nutr Metab 2012;60:196-199 
Table 1. Which ingredients are of greater or lesser concern?

Adding a 'component already present in human milk'

Ex. Taurine - same structure

Ex. $\alpha$-Lactalbumin - other species

Ex. Human recombinant lactoferrin
Issue: potency/concentration

Issue: amino acids/structure/function

Issue: glycosylation/function/impurities

Issue: tolerance, function

Issue: safety, function

Issue: amino acids/glycosylation/phosphorylation/function/potency

Ex. = Example

such as DHA (docosahexanoic acid), a long-chain polyunsaturated fatty acid being part of biological membranes, would warrant a different set of evaluations [16] than for example prebiotics, which can alter the balance of the gut microflora and also having biological activity [17]. Substances already present in human milk appeared to cause the IOM Committee less concern, but these substances include, for example, recombinant human milk proteins (table 1). If these proteins have no post-translational modifications (glycosylation, phosphorylation), they would be identical, whereas they otherwise may exert different effects, depending on the extent and nature of the modifications. Any impurities from the production system (microorganisms, cells, plants, and animals) need also to be considered. Other examples and the corresponding issues to address are listed in table 1.

Level 1 assessments include standard measures for each organ system (gastrointestinal, blood, kidney, immune, endocrine, and brain), whereas level 2 assessments include in-depth measures of organ systems that would be used to explicate equivocal level 1 findings or specific theoretical concerns not typically addressed by level 1 tests [8]. Again, the set of level 2 assessments will clearly depend on the nature of the compound evaluated and its potential bioactivity (table 2). For some compounds, isotope absorption tests may be relevant, while for others, specific histological stains or permeability tests may be used. Broadly, hematology and clinical chemistry will need to be evaluated, as well as gross pathology, histopathology, fecal microbiology, and potential mutagenicity. The extent to which modern methods in genomics and proteomics [18] may be used for assessment is uncertain, but it is likely they will have some applicability in these evaluation processes. Novel methods to evaluate outcomes, including metabolomics and molecular techniques to assess the microbiome, are also likely to be utilized.
Table 2. Gastrointestinal assessment: examples of tests at level 1 and $2^{*}$

\begin{tabular}{ll} 
Level 1 & $\begin{array}{l}\text { Absorption } \\
\text { Cell culture } \\
\text { Organ weight/histology }\end{array}$ \\
\hline Level 2 & $\begin{array}{l}\text { Isotope absorption tests } \\
\text { Microarrays/proteomics } \\
\text { Receptor expression } \\
\text { Specific histological stains } \\
\text { Permeability tests }\end{array}$
\end{tabular}

* The petitioner/manufacturer in consultation with the expert panel determines which tests are required based on a thorough analysis of the potential effects of the new ingredient (adapted from IOM, 2004).

\section{Concluding Remarks}

There are several aspects that need to be considered to improve processes to assess the safety of novel ingredients into formula. Among them are the establishment of expert panels (composition, qualifications, and integrity) and establishment of guidelines from regulatory agencies (including consensus on appropriate animal models). It is also important to introduce novel methods of analysis (genomics, proteomics) and outcomes (e.g., metabolomics).

\section{Disclosure Statement}

The author has nothing to disclose. 


\section{References}

$>1$ Aggett PJ, Agostini C, Goulet O, Hernell O, Koletzko B, Lafeber HL, Michaelsen KF, Rigo J, Weaver LT; European Society of Pediatric Gastroenterology, Hepatology and $\mathrm{Nu}$ trition (ESPGHAN) Committee on Nutrition: The nutritional and safety assessment of breast milk substitutes and other dietary products for infants: a commentary by the ESPGHAN Committee on Nutrition. J Pediatr Gastroenterol Nutr 2001;32:256-258.

$>2$ Life Sciences Research Office (LSRO): LSRO report: assessment of nutrient requirements for infant formulas. J Nutr 1998;128:2059S2293S.

$\checkmark 3$ Koletzko B, Baker S, Cleghorn G, Neto UF, Gopalan S, Hernell O, Hock QS, Jirapinyo P, Lönnerdal B, Pencharz P, Pzyrembel H, Ramirez-Mayans J, Shamir R, Turck D, Yamashiro Y, Zong-Yi D: Global standard for the composition of infant formula: recommendations of an ESPGHAN coordinated international expert group. J Pediatr Gastroenterol Nutr 2005;41:584-599.

4 Food and Drug Administration: Current good manufacturing practice, quality control procedures, quality factors, notification requirements, and records and reports, for the production of infant formula. Proposed rule. Fed Regist 1996;61:36153-36219.

5 Office of Food Additive Safety: Toxicological Principles for the Safety Assessment of Direct Food Additives and Color Additives Used in Food. Redbook II-Draft. Washington DC, OFAS, Center for Food Safety and Applied Nutrition, Food and Drug Administration, 2001
6 Grossklaus R: Codex recommendations on the scientific basis of health claims. Eur J Nutr 2009;48(suppl 1):S15-S22.

7 Koletzko B: Health claims: let science prevail. Ann Nutr Metab 2011;58:79-81.

8 Institute of Medicine: Infant formula: evaluating the safety of new ingredients. Wash ington, DC, National Academies Press, 2004

$\checkmark 9$ Houle VM, Schroeder EA, Odle J, Donovan SM: Small intestinal disaccharidase activity and ileal villus height are increased in piglets consuming formula containing recombinant human insulin-like growth factor-I. Pediatr Res 1997;42:78-86.

10 Herfel TM, Jacobi SK, Lin X, Walker DC, Jouni ZE, Odle J: Safety evaluation of polydextrose in infant formula using a suckling piglet model. Food Chem Toxicol 2009;47: 1530-1537.

11 Puiman PJ, Jensen M, Stoll B, Renes IB, de Bruijn AC, Dorst K, Schierbeek H, Schmidt M, Boehm G, Burrin DG, Sangild PT, van Goudoever JB: Intestinal threonine utilization for protein and mucin synthesis is decreased in formula-fed preterm pigs. J Nutr 2011;141:1306-1311.
12 Lönnerdal B, Jayawickrama L, Lien EL: Effect of reducing the phytate content and of partially hydrolyzing the protein in soy formula on zinc and copper absorption and status in infant rhesus monkeys and rat pups. Am J Clin Nutr 1999;69:490-496.

13 Lönnerdal B, Kelleher SL, Lien EL: Extent of thermal processing of infant formula affects copper status in infant rhesus monkeys. Am J Clin Nutr 2001;73:914-919.

14 Kelleher SL, Casas I, Carbajal N, Lönnerdal B: Supplementation of infant formula with the probiotic lactobacillus reuteri and zinc: impact on enteric infection and nutrition in infant rhesus monkeys. J Pediatr Gastroenterol Nutr 2002;35:162-168.

15 Brück WM, Kelleher SL, Gibson GR, Nielsen $\mathrm{KE}$, Chatterton DE, Lönnerdal B: rRNA probes used to quantify the effects of glycomacropeptide and alpha-lactalbumin supplementation on the predominant groups of intestinal bacteria of infant rhesus monkeys challenged with enteropathogenic Escherichia coli. J Pediatr Gastroenterol Nutr 2003;37:273-280.

16 Lien EL: Toxicology and safety of DHA. Prostaglandins Leukot Essent Fatty Acids 2009;81:125-132.

-17 Boyle FG, Wrenn JM, Marsh BB, Anderson WI, Angelosanto FA, McCartney AL, Lien EL: Safety evaluation of oligofructose: 13 week rat study and in vitro mutagenicity. Food Chem Toxicol 2008;46:3132-3139.

18 Daniel H: Genomics and proteomics: importance for the future of nutrition research. $\mathrm{Br}$ J Nutr 2002;87:S305-S311. 